\title{
Thickness and surface structure of a ceramic layer created on three indirect resin composites with aerosol deposition
}

\author{
*Yohsuke Taira, DDS, $\mathrm{PhD}^{\mathrm{a}}$, Hironori Hatono ${ }^{\mathrm{b}}$, Masahiro Tokita ${ }^{\mathrm{b}}$, \\ Takashi Sawase, DDS, $\mathrm{PhD}^{\mathrm{a}}$ \\ ${ }^{a}$ Department of Applied Prosthodontics
}

Graduate School of Biomedical Sciences, Nagasaki University, Nagasaki, Japan.

${ }^{b}$ Research Institute, TOTO Ltd., Chigasaki, Japan.

Type of article: Original research

Abbreviated title: Aerosol deposition on three resin composites

Key words: Resin composite, Ceramic, Surface modification

Address correspondence to: Yohsuke Taira

Department of Applied Prosthodontics

Graduate School of Biomedical Sciences, Nagasaki University

1-7-1, Sakamoto, Nagasaki 852-8588, Japan

Telephone: +81-95-819-7688, Fax: +81-95-819-7689

E-mail: yohsuke@,nagasaki-u.ac.jp 


\begin{abstract}
Purpose: Aerosol deposition is a technology for coating ceramics with impact consolidation at room temperature. The aim of the present study was to investigate the thickness and the microstructure of the aluminium oxide layer on different three dental resin composite materials created by means of aerosol deposition.
\end{abstract}

Methods: Disk-shaped specimens were fabricated with three resin composites (Estenia C\&B, Targis, and Gradia). The specimens were ground flat, and then subjected to aerosol deposition using aluminium oxide submicron particles without inducing a localized temperature rise. The average thickness (AVH) and maximum thickness (Hmax) of the aluminium oxide layer deposited on the resin composite material were measured using a profilometer. Data were analyzed by ANOVA and post-hoc Tukey Compromise test at $\alpha=0.05$. The specimen surfaces were also observed using a scanning electron microscope.

Results: The aluminium oxide layer formed on Estenia C\&B (AVH 8.1 $\mu$ m, Hmax $9.1 \mu \mathrm{m})$ and Targis (AVH $7.7 \mu \mathrm{m}, \mathrm{Hmax} 8.9 \mu \mathrm{m})$ were significantly thicker than that on Gradia (AVH $4.2 \mu \mathrm{m}$, Hmax 5.4). The micrograph showed that the aluminium oxide layer on Estenia C\&Bwas similar to that on Targis. However, the aerosol deposition area of Gradia was seen relatively rough and partly caved.

Conclusions: The type of resin composite affected the microstructure of the deposited aluminium oxide layer. The highly filled light- and heat-cured resin 
composites are advantageous as a target material rather than lower the filled lightcured resin composite. 


\section{Introduction}

Resin composite materials are used for fabricating aesthetic restorations, dentures, and orthodontic appliances. When compared to ceramic, resin composite has the advantages of adequate flexibility and easy handling. However, resin composite surfaces are abraded more easily than ceramic [1] or tooth enamel [2]. Although feldspathic porcelain is wear resistant, aesthetic, and does not stain, its handling is not easy, as it requires greater working time and a special furnace. Clinicians would therefore benefit from a novel technique that combines the advantageous properties of resin composite and porcelain.

Coating resin composite material with ceramics may improve surface characteristics[3]. Metal alloys and ceramics can be coated with chemical agents by techniques such as electroplating [4], sol-gel-derived coating [5,6], ion implantation $[7,8]$, plasma-sprayed coating $[9,10]$, chemical vapor deposition (CVD) [11,12], physical vapor deposition (PVD) [13,14], and sputter coating $[15,16]$. Without heating, it is impossible to form a dense ceramic film coating thicker than $1 \mu \mathrm{m}$; however, polymer may be denatured when the local temperature rises.

In the past decade, aerosol deposition has been employed to generate a ceramic coating [17-19]. Ceramic submicron particles were sprayed from a nozzle onto the target surface, and then the particles were collided. The collided ceramic particles 
turned into a rigid structure by reconstructing themselves. They were deposited continuously on the substrate as a dense ceramic layer. The coating process is completed at room temperature.

A variety of metal alloys, semiconductors, and ceramics could be used as the target. In a previous study, an aluminium oxide layer was successfully generated on a highly filled light- and heat-cured resin composite (Estenia, Kuraray Medical Inc., Tokyo, Japan) with aerosol deposition, and the resistance of the Estenia composite against toothbrush abrasion was significantly improved [20]. It was impossible to coat ceramic on a pure acrylic substrate. Thick and dense ceramic layer is helpful for the ceramic-coated restorations to withstand wear in oral environment. Although some types of resin composite materials are used for dental treatment, limited information is available regarding the possibility of aerosol deposition of ceramic coating on the resin composites.

The purpose of the present study was to investigate whether an aluminium oxide layer could be generated on three different types of resin composite by means of aerosol deposition. The null hypothesis tested was that the type of resin composite would not affect the thickness and microstructure of the deposited aluminium oxide layer. 


\section{Materials and methods}

\section{Specimen preparation}

The three resin composites used were Estenia C\&B (Kuraray Medical Inc., Tokyo Japan), Targis (Ivoclar Vivadent Inc., Amherst, NY), and Gradia (GC Corp., Tokyo, Japan) (Table 1). Estenia C\&B was composed of small splintered inorganic fillers (average $0.02 \mu \mathrm{m}$ ), large splintered inorganic fillers (average 1.5-2.0 $\mu \mathrm{m}$ ), and methacrylates. The inorganic component of Estenia C\&B was reported $87.9 \mathrm{wt} \%$ [21] or $88.6 \mathrm{wt} \%$ [22]. Targis contained splintered barium glass (average 0.03-1.0 $\mu \mathrm{m})$, colloidal silica, and methacrylates. The inorganic component was reported 72.6wt $\%$ [21]. Gradia was composed of large prepolymerized composite filler containing silica, splintered inorganic filler (average $1.0 \mu \mathrm{m}$ ), and methacrylates. The inorganic component was reported $54.1 \mathrm{wt} \%$ [21] or $54.4 \mathrm{wt} \%$ [22]. An acrylic ring (10 $\mathrm{mm}$ in diameter inside and $3 \mathrm{~mm}$ in thickness) was placed on a micro cover glass, filled with the composite material, and then covered with another micro cover glass. In the Estenia C\&B specimen, both the flat surfaces were lightcured for $300 \mathrm{~s}$ ( $\alpha$-light II, Morita Corp., Tokyo, Japan), and heat-cured at $110^{\circ} \mathrm{C}$ for 15 min (KL100, Kuraray Medical). The Targis specimen was light- and heatcured with a curing apparatus (Targis Power, Ivoclar Vivadent Inc., Anherst, NY, USA) according to the manufacturer's instructions. In the Gradia specimen, both the flat surfaces were light-cured for $300 \mathrm{~s}$ ( $\alpha$-light II). One specimen was 
fabricated with each resin composite. The micro cover glass and acrylic ring were removed, the specimens were ground on 600-grit silicon-carbide paper, polished with $1-\mu \mathrm{m}$ diamond paste, wiped with alcohol, and then ultrasonically rinsed in water for $5 \mathrm{~min}$.

\section{Aerosol deposition}

After a masking tape was attached to half the area of the specimen, an aluminium oxide layer was generated on the specimen by means of an experimental aerosol deposition apparatus using aluminium oxide particles of $0.6-\mu \mathrm{m}$ average particle size as a raw material at room temperature (Fig. 1). The aluminium oxide particles were pulverized polycrystals of $\alpha-\mathrm{Al}_{2} \mathrm{O}_{3}$. The aerosol was produced by mixing nitrogen gas and the aluminium oxide fine particles and it was accelerated by a differential pressure of $55 \mathrm{kPa}$. It was then sprayed from a rectangular nozzle (10 $\mathrm{mm} \times 0.4 \mathrm{~mm}$ ) onto the specimen in the chamber. During deposition, the flow of nitrogen gas was controlled at $5 \mathrm{~L} / \mathrm{min}$ by a vacuum pump. Actuating the $\mathrm{XY}$ actuator with the specimen, the aluminium oxide layer was formed over the intended area of the specimen (Fig. 2). 


\section{Profilometric tracing}

Following aerosol deposition, the masking tape was removed, and the specimen was ultrasonically rinsed in water for $5 \mathrm{~min}$. The thickness of the deposited aluminium oxide layer on the resin composite material was measured in micrometers with a profilometer (Surfcom 480A, Tokyo Seimitsu Co., Ltd., Tokyo, Japan). The scanning length and scanning speed were set at $2000 \mu \mathrm{m}$ and $0.3 \mathrm{~mm} / \mathrm{s}$, respectively. The average thickness (AVH) and maximum thickness (Hmax) of the aluminium oxide layer deposited on the resin composite material were recorded in micrometers, when the eliminate length to read was set at $150 \mu \mathrm{m}$. Six separate profilometric tracings were made at $1 \mathrm{~mm}$ intervals. The mean and standard deviation of the six readings were calculated. The data were analyzed by one-way analysis of variance (ANOVA) and post-hoc Tukey Compromise test ( $\alpha=0.05)$.

\section{Scanning electron microscopy}

The deposited surfaces were sputter-coated with gold (Ion Coater IB-3, Eiko Engineering Co. Ltd, Hitachinaka, Japan), and then observed using a scanning electron microscope (S-3500N, Hitachi Ltd., Tokyo, Japan) with a magnification of $1000 \times$. 


\section{Fabrication of a jacket crown with aerosol deposition}

A jacket crown was fabricated with Estenia $\mathrm{C} \& \mathrm{~B}$ on an abutment model according to the manufacturer's instructions. A masking tape was attached to the left area of the labial surface, and then it was subjected to the aerosol deposition as described. After removing the masking tape, the surface was polished with a $3-\mu \mathrm{m}$ diamond paste (SP-0, Asahi Diamond Industrial Co. Ltd., Tokyo, Japan).

\section{Results}

The results of one-way ANOVA showed a significant effect for the type of resin composite in AVH and Hmax (Table 2). The means and standard deviations of AVH and Hmax recorded on the three resin composites are listed in Table 3. The values of AVH and Hmax ranged from 4.2-8.1 and 5.4-9.1, respectively. Estenia C\&B and Targis were not significantly different. Gradia showed significantly smaller AVH and Hmax values than Estenia C\&B and Targis.

The profilometric tracing showed a clear demarcation at the center, which was the border between the areas with and without aluminium oxide layer (Fig. 3). The control area without aluminium oxide layer was on the left side of the specimen and the deposited area was on the right side. With regard to the control area, no clear difference was found between Estenia C\&B, Targis, and Gradia. In Estenia 
$\mathrm{C} \& \mathrm{~B}$ and Targis, the traced lines showed similar patterns and the deposited aluminium oxide layer was relatively thick at the interface with and without aerosol deposition. In contrast to Estenia $\mathrm{C} \& \mathrm{~B}$ and Targis, the aerosol deposition area of Gradia was rough and partly caved.

Figs. 4(a) $-4(c)$ show the micrographs of specimen surfaces consisting of a non-aerosol deposition area (A) and an aerosol deposition area (B). Both the deposited surfaces of Estenia C\&B and Targis were smooth. On the other hand, a number of crater like structure were observed in the deposited surfaces of Gradia. Gradia also showed the edge of aluminium oxide layer was peeled widely.

Fig. 5 is the jacket crown fabricated with the Estenia $\mathrm{C} \& \mathrm{~B}$ composite. The right area was deposited with aluminium oxide. When compared to the non-aerosol deposition area, the deposited area was visually transparent and glossy.

\section{Discussion}

Aerosol deposition is a new technology for coating ceramics with impact consolidation at room temperature. In the present study, a 7 - to $9-\mu \mathrm{m}$-thick translucent aluminium oxide layer was deposited on two resin composites (Estenia $\mathrm{C} \& \mathrm{~B}$ and Targis) without inducing a localized temperature rise. The profilometric tracing results showed a clear demarcation at the interface with and without aerosol 
deposition (Figs. 4(a) - (c)). Calculating AVH and Hmax, a distance of $150 \mu \mathrm{m}$ was eliminated from the edge in order to exclude the artifact peak induced. (Fig. 3). When the thickness of the aluminium oxide layer exceeded approximately 10 $\mu \mathrm{m}$, the deposited layer partly peeled in these composites. On the contrary, if the aluminium oxide layer is too thin, it may be disappeared by tooth brushing or by occlusal wear. The previous in vitro study suggested that $5-\mu \mathrm{m}$ thickness is enough to survive 100,000 cycles of toothbrush abrasion [20].

It is reported when an aerosol containing submicron particles of a brittle material is spurted out from a nozzle onto the target surface, the particles collide and are attached to the target, resulting in a new deposited surface. The collided particles bond to each other, are deposited continuously on the substrate, and a dense layer with a nano-crystal structure is formed [17,19]. A variety of brittle materials such as titanium oxide, zinc oxide, iron oxide, zirconium oxide, yttrium oxide, silicon oxide, aluminium nitride, barium titanate, calcium titanate, and strontium titanate could be applied, but aluminium oxide was selected because of its transparency, superior hardness, biological safety, and reliability [19].

A ceramic layer cannot be deposited on pure acrylic substrate, because the aerosol jet strips the surface. The inorganic filler content was reported to be $87.9 \mathrm{wt} \%$ or $88.6 \mathrm{wt} \%$ for Estenia C\&B, $72.6 \mathrm{wt} \%$ for Targis, and $54.1 \mathrm{wt} \%$ or $54.4 \mathrm{wt} \%$ for Gradia $[21,22]$. We speculated therefore that the aluminium oxide 
layer bonds directly to the inorganic components of the target resin composite, and the thickness of the deposited aluminium oxide layer depends upon the inorganic filler content. It should be also acknowledged that many factors influence the aerosol deposition, such as quality of the filler, volume percent of the inorganic components, and dispersion of filler particles. Although no definitive borderline can be drawn without these informations, resin composites containing inorganic fillers over $70 \mathrm{wt} \%$ was advantageous for aluminium oxide coating by aerosol deposition.

On Gradia, many caves and ditches were observed (Fig. 4(c)). Although Gradia contained only a total of $54 \mathrm{wt} \%$ inorganic filler, the prepolymerized composite fillers were composed of $83 \mathrm{wt} \%$ inorganic filler and $17 \mathrm{wt} \%$ methacrylates [21]. The present findings suggest that the aluminium oxide layer was generated on the prepolymerized composite fillers [23] rather than on the matrix area. This may be the reason why the crater like structure was observed. Taking the clinical situation into account, it is concern that the transparency is decreased or plaque is retained at the crater area.

Fig. 5 suggests that the curved surface including the marginal area can be deposited with aluminium oxide layer as well as the flat surface of the disk specimen. These indirect restorations provided with the aerosol deposition may have advantageous properties both of resin composite and porcelain. Minimal 
exposure of the organic component would improve the abrasion resistance of restorations, and prevent the surface from staining in the oral environment. Although the aerosol deposition has a potential to modify jacket crowns, composite veneered crowns, or composite inlays, it still has a disadvantage that ceramic coating on the incisal edge or the occlusal surface is difficult, because of the limitation of the $\mathrm{XY}$ actuator used. Therefore, it is required to develop the aerosol deposition apparatus and verify the long-term stability of such deposited ceramics layers in future.

\section{Conclusions}

Within the limits of the present investigation, it was concluded that dense aluminium oxide layer was formed on the highly filled resin composites (Estenia $\mathrm{C} \& \mathrm{~B}$ and Targis) by means of aerosol deposition without inducing a localized temperature rise. In contrast, a number of crater like microstructure were observed in the deposited surfaces of Gradia. The null hypothesis was rejected because it was demonstrated that the deposited aluminium oxide layers on the lower filled resin composite (Gradia) was significantly thinner than those on Estenia $\mathrm{C} \& \mathrm{~B}$ and Targis. 


\section{References}

[1] Yesil Duymus Z, Orbak R, Dilsiz A. Abrasion resistance of veneering materials to tooth brushing. Dent Mater J 2003;22:460-6.

[2] Heath JR, Wilson HJ. Abrasion of restorative materials by toothaste. J Oral Rehabil 1976;3:121-38.

[3] Hotta M, Hirukawa H. Abrasion resistance of restorative glass-ionomer cements with a light-cured surface coating. Oper Dent 1994;19:42-6.

[4] Karlsson S, Molin M, Myrvold T. Flexural strength of two electro-plated dental ceramics. Acta Odontol Scand 1994;52:290-3.

[5] Filiaggi MJ, Pilliar RM, Abdulla D. Evaluating sol-gel ceramic thin films for metal implant applications. II. Adhesion and fatigue properties of zirconia films on Ti-6AI-4V. J Biomed Mater Res 1996;33:239-56.

[6] Bae IJ, Standard OC, Roger GJ, Brazil D. Phase and microstructural development in alumina sol-gel coatings on $\mathrm{CoCr}$ alloy. J Mater Sci Mater Med 2004;15:959-66.

[7] Sawase T, Wennerberg A, Baba K, Tsuboi Y, Sennerby L, Johansson CB, et al. Application of oxygen ion implantation to titanium surfaces: effects on surface characteristics, corrosion resistance, and bone response. Clin Implant Dent Relat Res 2001;3:221-9. 
[8] Buchanan RA, Rigney ED Jr, Williams JM. Ion implantation of surgical Ti-6Al-4V for improved resistance to wear-accelerated corrosion. J Biomed Mater Res 1987;21:355-66.

[9] Heimann RB, Kurzweg H, Ivey DG, Wayman ML. Microstructural and in vitro chemical investigations into plasma-sprayed bioceramic coatings. J Biomed Mater Res 1998;43:441-50.

[10] Whitehead RY, Lacefield WR, Lucas LC. Structure and integrity of a plasma sprayed hydroxylapatite coating on titanium. J Biomed Mater Res $1993 ; 27: 1501-7$.

[11] Catledge SA, Fries MD, Vohra YK, Lacefield WR, Lemons JE, Woodard S, et al. Nanostructured ceramics for biomedical implants. J Nanosci Nanotechnol 2002;2:293-312.

[12] Wagner WC. A brief introduction to advanced surface modification technologies. J Oral Implantol 1992;18:231-5.

[13] Schäfer E. Effect of physical vapor deposition on cutting efficiency of nickel-titanium files. J Endod 2002;28:800-2.

[14] Hendry JA, Pilliar RM. The fretting corrosion resistance of PVD surfacemodified orthopedic implant alloys. J Biomed Mater Res 2001;58:156-66. 
[15] Lee KM, Cai Z, Griggs JA, Guiatas L, Lee DJ, Okabe T. SEM/EDS evaluation of porcelain adherence to gold-coated cast titanium. J Biomed Mater Res B Appl Biomater 2004;68:165-73.

[16] Bullard JT, Dill RE, Marker VA, Payne EV. Effects of sputtered metal oxide films on the ceramic-to-metal bond. J Prosthet Dent 1985;54:776-8.

[17] Akedo J, Lebedev M. Microstructure and electrical properties of lead zirconate titanate $\left(\mathrm{Pb}\left(\mathrm{Zr}_{52} / \mathrm{Ti}_{48}\right) \mathrm{O}_{3}\right)$ thick films deposited by aerosol deposition method. Jpn J Appl Phys 1999;38:5397-401.

[18] Akedo J, Minami N, Fukuda K, Ichiki M, Maeda R. Electrical properties of direct deposited piezoelectric thick film formed by gas deposition method. Ferroelectrics 1999;231:285-92.

[19] Tsujimichi K, Mori K, Yoshida A, Iwasawa J, Hatono H, Kiyohara M. Mechanical and electrical properties of $\mathrm{Al}_{2} \mathrm{O}_{3}$ thin films on metals, ceramics and resins prepared by aerosol deposition method. Ceramic Engineering \& Science Proceedings 2003;24:121-5.

[20] Taira Y, Hatono H, Mizukane M, Tokita M, Atsuta M. Effect of ceramic coating by aerosol deposition on abrasion resistance of a resin composite material. Dent Mater J 2006;25:700-5. 
[21] Izumida A, Tomota K, Kimura K, Komatsu M, Okuno O. Rheological study of hard resin for crown and bridge. J Jpn Prosthodont Soc 2006;50:396-404.

[22] Hirose H, Kawamoto Y, Kojima T, Sakaguchi S, Kimura K, Saitoh M, et al. Density, polymerization shrinkage, filler content and coefficient of thermal expansion of composite resins for crown and bridge. J J Dent Mater 2006;25:62-8.

[23] Suzuki S, Nakabayashi N, Masuhara E. The evaluation of new dental resins prepared with polyfunctional methacrylate monomers. J Biomed Mater Res 1982;16:275-87. 


\section{Table 1}

Three resin composite materials used in the present study.

Name (Color) Manufacturer $\quad$ Lot No. Inorganic component

$(\mathrm{wt} \%)$

Estenia C\&B (E1) Kuraray Medical Inc., $\quad$ 0016BA $87.9^{*} \quad 88.6^{*}$

Tokyo, Japan

Targis (S2) Ivoclar Vivadent Inc., $\quad$ F44880 $\quad 72.6^{*}$

Amherst, NY, USA

$\begin{array}{llll}\text { Gradia (E3) } \quad \text { GC Corp., } & 0508091 & 54.1^{*} & 54.4^{*}\end{array}$

Tokyo, Japan

*data quoted from the research reports $[21,22]$ 


\section{Table 2}

Results of analysis of variance (ANOVA)

a) ANOVA corresponding to average thickness (AVH)

Source df Sum of Squares Mean Square F-value P-value

$\begin{array}{llllll}\text { Resin composite } & 2 & 56.5 & 28.3 & 429.1 & 0.0001\end{array}$

$\begin{array}{llll}\text { Residual } & 15 & 1.0 & 0.1\end{array}$

b) ANOVA corresponding to maximum thickness (Hmax)

Source df Sum of Squares Mean Square F-value P-value

$\begin{array}{llllll}\text { Resin composite } & 2 & 53.4 & 26.7 & 337.9 & 0.0001\end{array}$

$\begin{array}{llll}\text { Residual } & 15 & 1.2 & 0.1\end{array}$ 


\section{Table 3}

Average thickness (AVH) and maximum thickness

(Hmax) of the deposited aluminium oxide layer.

AVH (SD) $(\mu \mathrm{m}) \quad H \operatorname{Hmax}(\mathrm{SD})(\mu \mathrm{m})$

$\begin{array}{lll}\text { Estenia C\&B } & 8.1(0.3)^{\mathrm{a}} & 9.1(0.4)^{\mathrm{A}} \\ \text { Targis } & 7.7(0.1)^{\mathrm{a}} & 8.9(0.1)^{\mathrm{A}} \\ \text { Gradia } & 4.2(0.3)^{\mathrm{b}} & 5.4(0.2)^{\mathrm{B}}\end{array}$

$\mathrm{AVH}$ and Hmax values assigned the same letters in each column indicate no statistically significant difference, as determined by Tukey Compromise test $(\mathrm{p} \geq 0.05)$. 


\section{Legends to Figures}

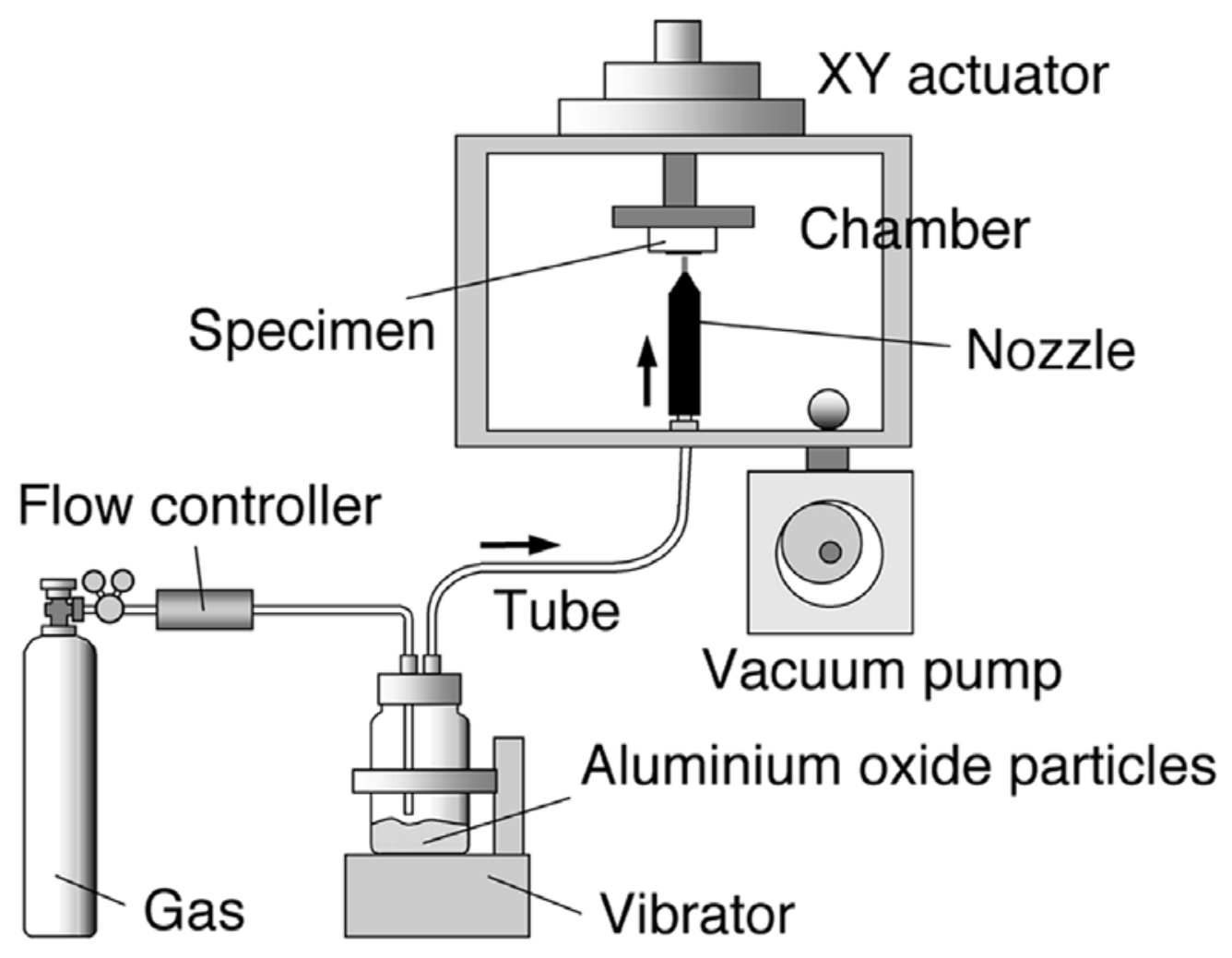

Fig. 1. Schematic illustration of the apparatus used for ceramic coating by aerosol deposition. 


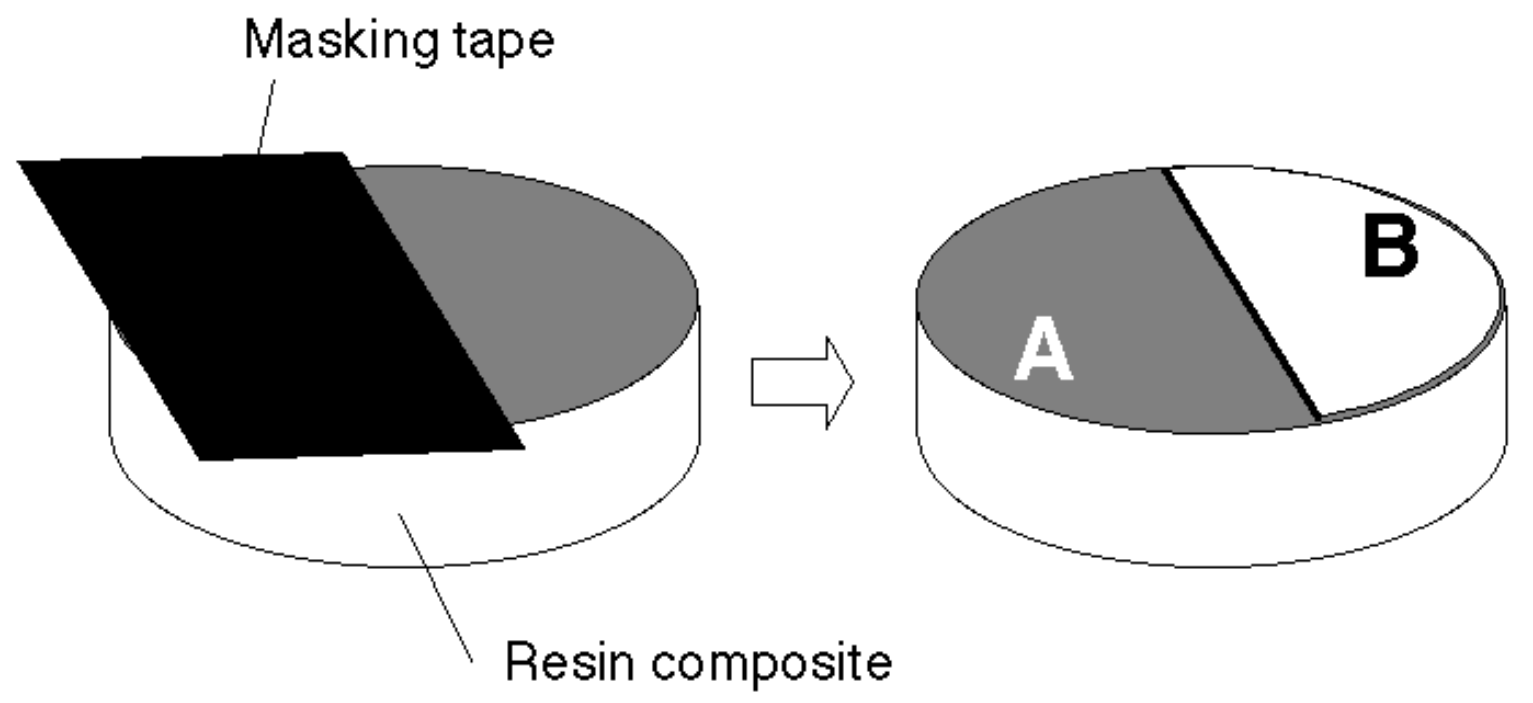

Fig. 2. Schematic illustration of the specimen. A: the non-aerosol deposition area, B: aerosol deposition area. 


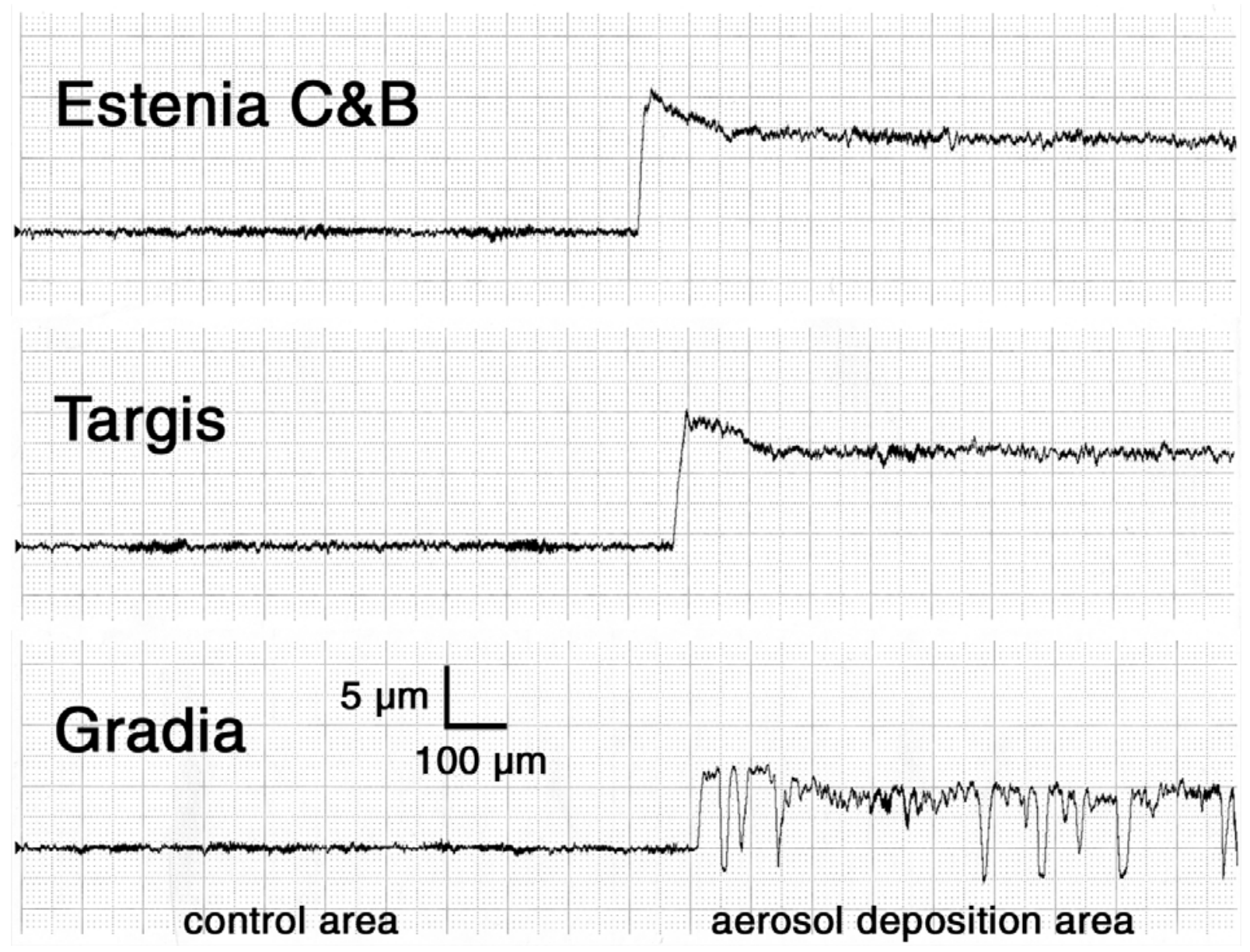

Fig. 3. Representative records of the profilometric tracing for Estenia C\&B, Targis, and Gradia. 
(a)

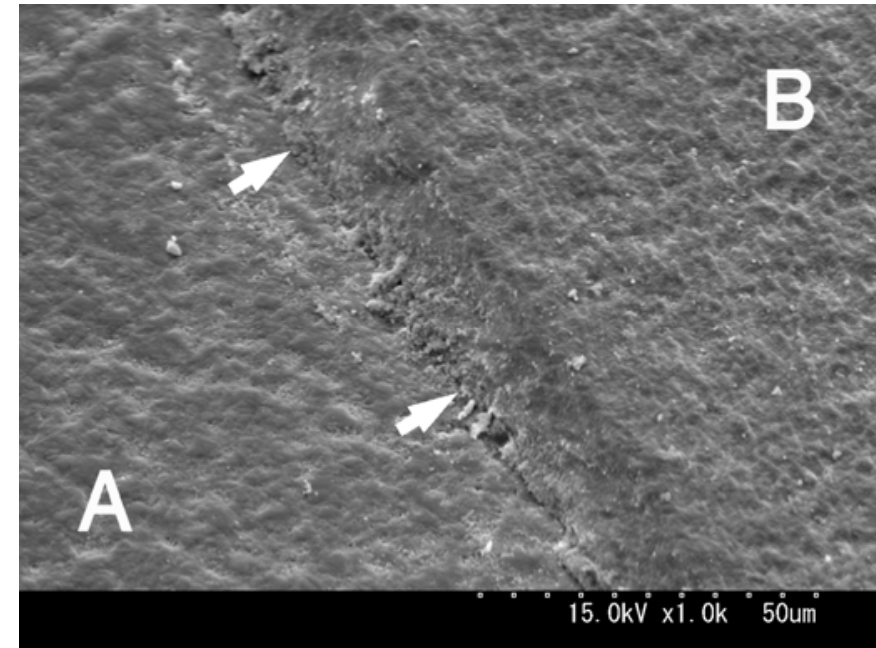

(b)

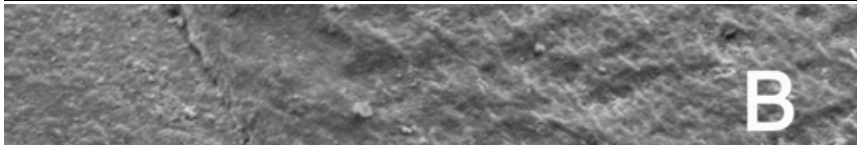

(c)
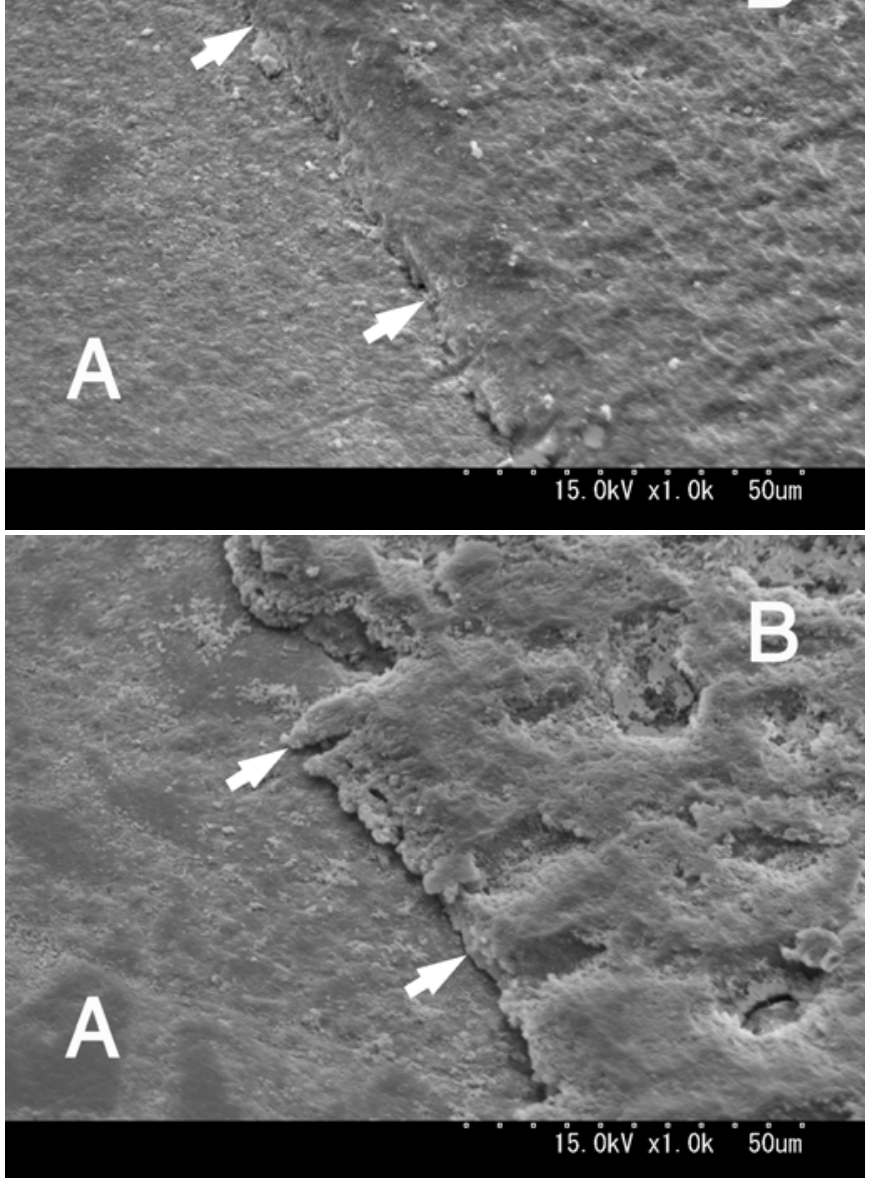

Fig. 4. (a) Micrograph of the Estenia $C \& B$ specimen. Arrows indicated the borderline of the deposited aluminium oxide layer. (b) Micrograph of the Targis specimen. (c) Micrograph of the Gradia specimen. 


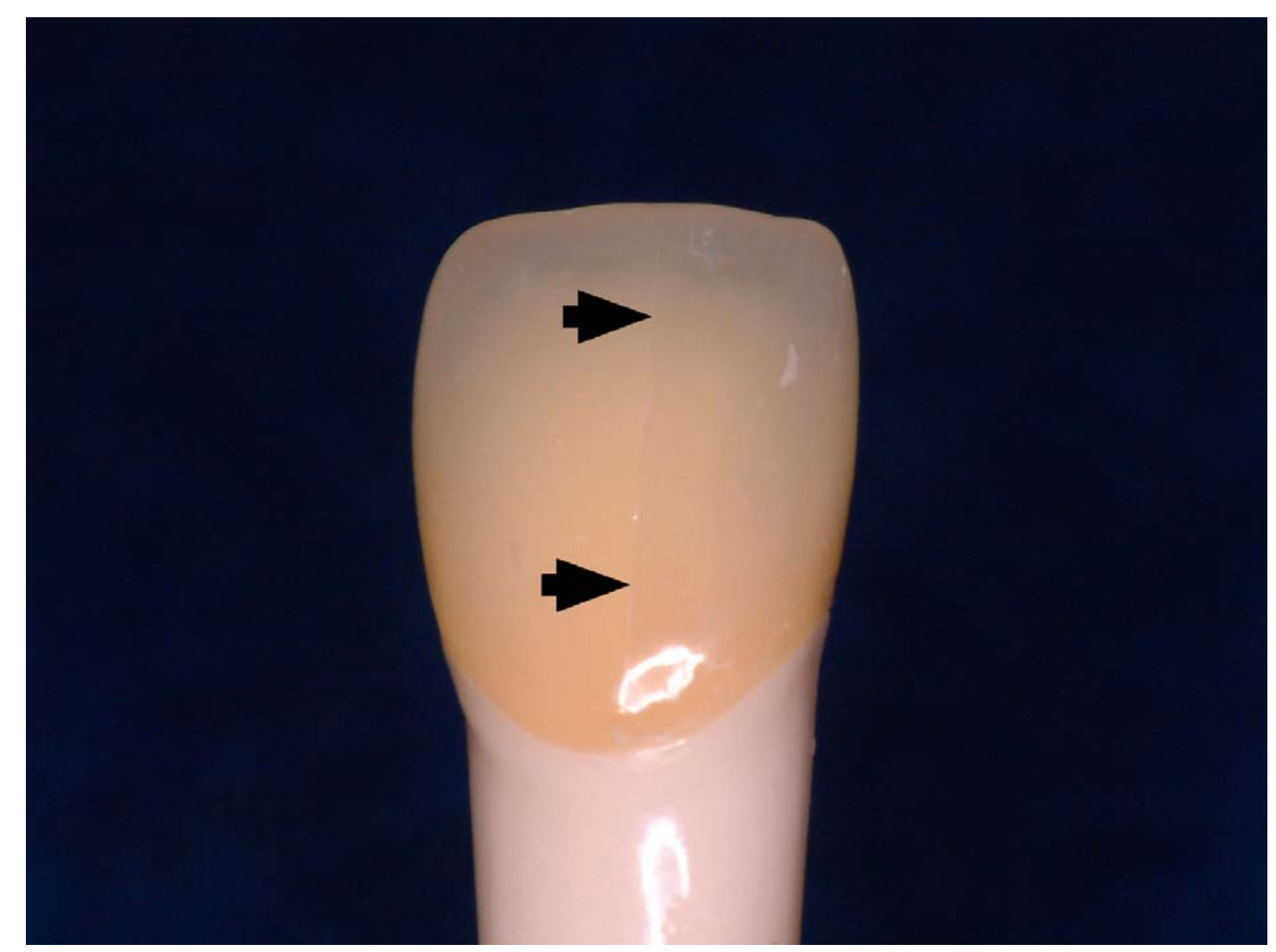

Fig. 5. A jacket crown fabricated with Estenia $C \& B$, the right area of which was deposited with aluminium oxide by means of aerosol deposition. Arrows indicated the borderline of deposited area. 